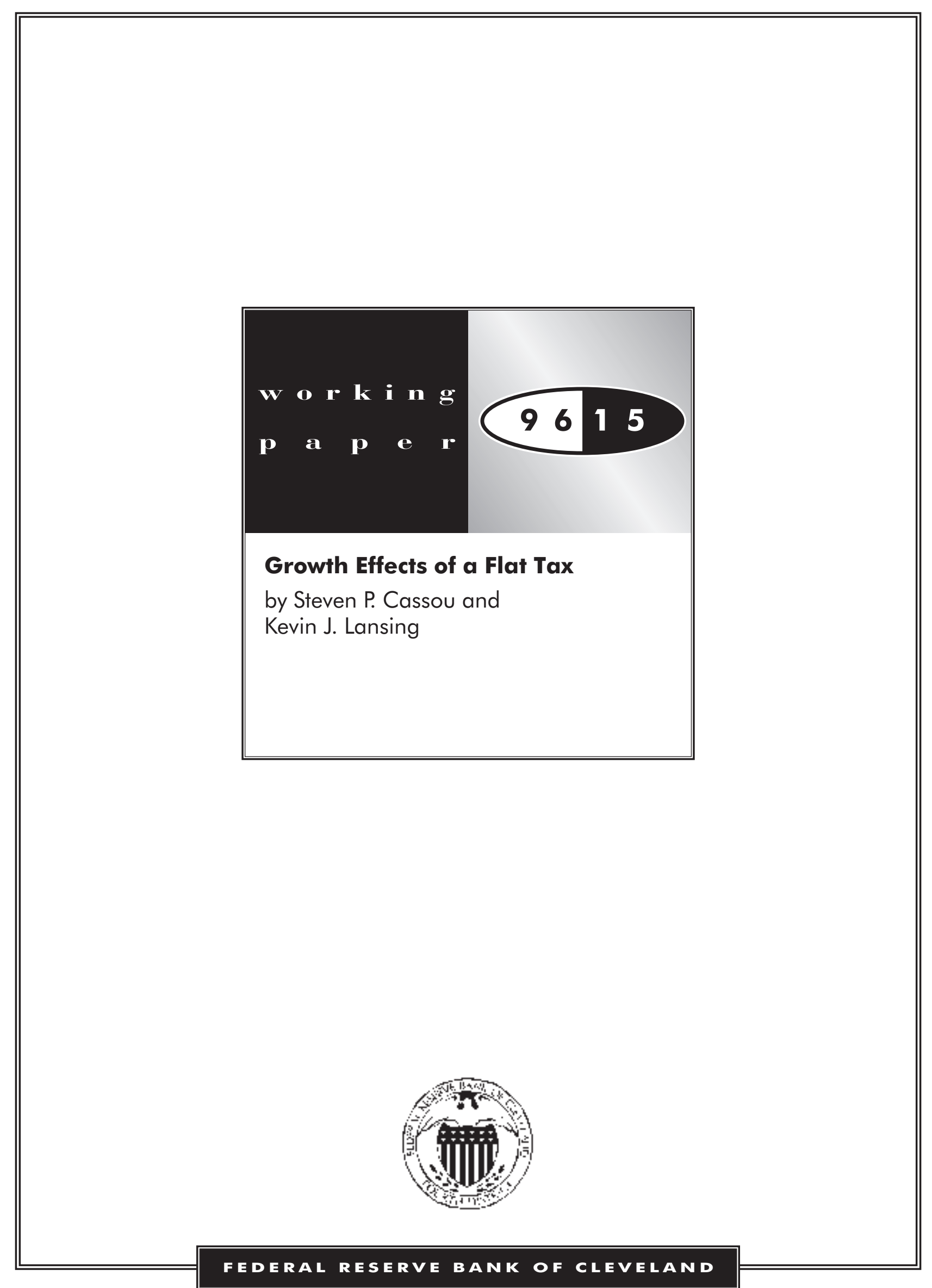


Working Paper 9615

\section{GROWTH EFFECTS OF A FLAT TAX}

by Steven P. Cassou and Kevin J. Lansing

Steven P. Cassou is an assistant professor of economics at Kansas State University, and Kevin J. Lansing is an economist at the Federal Reserve Bank of Cleveland. For helpful comments and suggestions, the authors would like to thank David Altig, Charles Carlstrom, James Dow, William Gale, Greg Huffman, Kenneth Judd, Rodi Manuelli, Alvin Rabushka, Ben Russo, and Peter Rupert.

Federal Reserve Bank of Cleveland working papers are preliminary materials distributed to promote discussion and critical comment on research in progress. These papers may not have been subject to the formal editorial review accorded the Bank's official publications.

The views stated herein are those of the authors and are not necessarily those of the Federal Reserve Bank of Cleveland or of the Board of Governors of the Federal Reserve System.

Working papers are now available electronically through the Bank's home page on the World Wide Web:

http://www.clev.frb.org.

December 1996 


\begin{abstract}
This paper develops a quantitative general equilibrium model to assess the growth effects of adopting a flat tax plan similar to the one proposed by Hall and Rabushka $(1985,1995)$. Using parameters calibrated to match the progressivity of the U.S. federal tax schedule and other features of the U.S. economy, we find that a revenue neutral flat tax can permanently increase per capita growth by 0.18 to 0.85 percentage points per year. Both features of a flat tax-the lower marginal tax rate and the full investment write-off-are important contributors to the growth gain. The strength of the growth effect depends on: (1) the elasticity of household labor supply, (2) capital's share of output, and (3) the elasticity of the capital stock with respect to new investment.
\end{abstract}




\section{Introduction}

Since its inception in 1913, the U.S. federal income tax system has grown enormously, in terms of the revenues raised, and the shear number of pages and complexity of the Internal Revenue Service code. The system has been accused of costing the U.S. economy billions of dollars in lost output each year because of the perverse way that it affects people's incentives to work, save, invest, and take entrepreneurial risks. On top of that, taxpayers must spend huge numbers of hours learning about and complying with rules that are described as being too complicated for the ordinary citizen to understand.

Criticisms such as these have led to calls for a simpler and more efficient federal income tax. One of the most widely discussed proposals for achieving this goal is a so-called flat tax. The basic idea of a flat tax is to have only one tax rate which applies to all taxable income. This contrasts sharply with the current system which has five tax rates ranging from 15 to 39.6 percent, each applied to a different increment of income. The current system is often described as "progressive" because the marginal tax rate-the rate applied to the last dollar of income-goes up as one's income rises. A flat tax can also exhibit features that are progressive, however, through the appropriate use of a standard personal deduction.

In addition to having only one rate, another key feature of a flat tax is the definition of taxable income. The underlying principle is that individuals should be taxed on what they take ont if the ecomomy (consumption), and not what they put in (savings or investment). The effect of a consumption tax can be achieved by allowing investment expenditures w b fully deducted, or "written-off," from taxable income. This cnhances and simplifies the variety of investment incentives that are built into the current system. wh as acclerated depreciation schedules, partial interest deductibility. and so (un.

The currem debate wer a llat wax has bern stimulated in large measure by Hall and Rabushka (1985, 1995). Whedescribe the flat tax proposal in very simple terms and work out the practical details nerded for its implementation. Hall and Rabushka argue that the adeption of a flat lax womld give an enormous boost to the U.S. 
economy by dramatically improving incentives to engage in productive activities and would save taxpayers hundreds of billions of dollars in compliance and administration costs.

In this paper, we develop a quantitative general equilibrium model to assess the growth effects of a adopting a flat tax plan similar to the one proposed by Hall and Rabushka. The framework for our analysis is a simple endogenous growth model in which the progressivity of the tax schedule is summarized by a single parameter. This parameter captures the way in which agents' incentives to consume, work, and invest are influenced by rising marginal tax rates. Relative to a progressive tax system, we find that a flat tax leads to an increase in labor hours, income, and investment (or savings). The initial impact on consumption is ambiguous: there is a positive effect due to an increase in income, but a negative effect due to a lower marginal propensity to consume. However, since labor hours and investment are the driving forces for growth in our model, a flat tax raises the economy's long-run growth rate, and hence, long-run consumption. This results in large welfare gains.

Our model builds on the recent work of Stokey and Rebelo (1995) who use an endogenous growth framework to identify the key model features and parameters that are important for determining the quantitative impacts of tax reform on growth. ${ }^{1}$ Our analysis differs from theirs in two fundamental respects.

First, we evaluate the growth effects of switching from a progressive tax to a flat tax. In doing so, we consider the gains attributable to both the lowering of the marginal tax rate and the full write-off of investment expenditures. Stokey and Rebelo consider only tax systems in which the marginal tax rate is equal to the average tax rate. Moreover, while their analysin examines the impact of a depreciation allowance, they do not consider a full imestment write-off.

Second, human capital in our model accumulates via a "learning by doing" externality instead of through direct incestment expenditures by households. Our formulation implies that households underimest in human capital relative to the socially

\footnotetext{
'Some other rescarch that considern the effects of tax reform on growth includes King and Rebelo (1990), Lucas (1990), Relelo (1991), Pecorinu (1993, 1994), Jones, Manuelli, and Rossi (1993), Devereux and Love (1994), and (ilomm and Ravikumar (1996), among others.
} 
optimal level. This tends to magnify the growth effects of reforms that affect investment incentives. In a sensitivity analysis, we investigate the impact of the learning by doing externality on the computed growth gains.

Using parameters calibrated to match the progressivity of the U.S. federal tax schedule and other features of the U.S. economy, we quantify the growth effects of a flat tax. In switching from a progressive tax system to a flat tax, we impose a condition of revenue neutrality. A flat tax results in a lower marginal tax rate, but requires a higher average tax rate to pay for the more generous write-off and deduction features. This mitigates the resulting growth benefits.

In our experiments, we find that a flat tax can permanently increase per capita growth by 0.18 to 0.85 percentage points per year. Both features of a flat tax-the lower marginal tax rate and the full investment write-off-are important contributors to the growth gain. The lower marginal tax rate accounts for about two-thirds of the gain, while the full write-off accounts for one-third. We show that the strength of the growth effect depends on: (1) the elasticity of household labor supply, (2) capital's share of output, and (3) the elasticity of the capital stock with respect to new investment.

For a baseline set of parameters, a flat tax increases annual per capita growth by 0.74 percentage points, from 1.80 percent to 2.54 percent. This growth effect is well within the range of values that have been cited in the public debate surrounding a flat tax. For example, former presidential candidate Steve Forbes argued that a flat tax would increase growth by 2 percentage points or more per year. Alvin Rabushla has asserted that annual growth would increase by 1 percentage point or more for at least seven years. Robert Barro estimates that annual growth would increase by roughly 0.4 percentage points. ${ }^{2}$

Some words of caution regarding the interpretation of our results are in order. First, although our model provides a theoretical framework for evaluating claims regarding the growth benefits of a flat tax, the empirical evidence regarding the links

\footnotetext{
${ }^{2}$ Sources for these figures are as follows: The Wall Street Journah January 29, 1996, page A-1, column 5 (Forbes), The New York Times, January 23, 1996, page A-11, column 1 (Rabushka), and The Wall Street Jouraah Fobruary 22, 1996 , page A-14, column 4 (Barro).
} 
between tax policy and long-run growth are inconclusive. ${ }^{3}$ Second, our results, like those of Stokey and Rebelo (1995), show that the effects of tax reform on growth are sensitive to the choice of parameter values. Third, since our model abstracts from stochastic shocks, we allow no role for progressive taxes to serve as potentially beneficial automatic stabilizers. ${ }^{4}$ Fourth, our highly stylized model assumes that all households are identical. Thus, while our model can address issues of efficiency and growth, it cannot be used to evaluate questions of distribution and fairness. What can be said in this regard is that by enlarging the entire social pie, a higher growth rate may provide significant benefits even to those who hold smaller shares of the pie.

The remainder of the paper is organized as follows. Section 2 describes the model. Section 3 derives the household decision rules and shows how the tax system influences economic incentives and the per capita growth rate. Section 4 describes how we calibrate our model to capture various features of the U.S. economy. Section 5 presents our quantitative results. Section 6 concludes.

\section{The Model}

The model economy consists of a large number of identical, infinitely-lived households that operate in competitive markets, and the government. Each household operates a firm that produces goods which are sold in the market. Households make decisions about how much to consume, work, and invest over their lifetimes. In doing so, they take into account the way in which the tax system affects their earnings. The government sets the rules that govern the tax system. Tax revenues collected from households are used to finance public expenditures. In what follows, we describe each of these features of the economy in more detail.

\footnotetext{
sSer Ireland (1994) for a review of the empirical evidence

${ }^{4}$ See Miller (1984) for a model that addressest this issue.
} 


\subsection{Households}

The household's decision problem can be formulated as choosing $\left\{c_{t}, l_{t}, y_{t}, i_{t}, k_{t+1}, \tau_{t}\right\}_{t=0}^{\infty}$ in order to maximize

$$
\sum_{t=0}^{\infty} \beta^{t} \ln \left(c_{t}-B h_{t} l_{t}^{\gamma}\right), \quad \beta \in(0,1), \quad B>0, \quad \gamma>1
$$

subject to

$$
\begin{aligned}
& c_{t}+i_{t}=y_{t}-\tau_{t}\left(y_{t}-\phi i_{t}-D_{t}\right), \quad \phi \in[0,1], \\
& y_{t}=A_{0} k_{t}^{\theta}\left(h_{t} l_{t}\right)^{1-\theta}, \quad A_{0}>0, \quad \theta \in(0,1], \\
& k_{t+1}=A_{1} k_{t}^{1-\delta} i_{t}^{\delta}, \quad A_{1}>0, \quad \delta \in(0,1], \quad k_{0} \text { given, } \\
& \tau_{t}=F\left(y_{t}, i_{t}\right),
\end{aligned}
$$

where $\beta$ is the discount factor, $c_{t}$ is consumption, $l_{t}$ is hours worked, and $h_{t}$ is an index of knowledge (or human capital) which is outside of the household's control.

Equation (2) is the household's within-period budget constraint, where $i_{t}$ is investment (or savings), $y_{t}$ is pre-tax income and $\tau_{t}$ is the income tax rate. Taxable income is given by $y_{t}-\phi i_{t}-D_{t}$, where $\phi$ is the fraction of investment expenditures that can be "expensed" or written-off from taxable income, and $D_{t}$ is the standard deduction which households take as given. For comparison with U.S. tax law, $\phi$ can be viewed as an index number that summarizes the various elements of the tax code that encourage investment. For our purposes, the most important of these is the capital depreciation allowance. ${ }^{5}$

We model households as entrepreneurs who operate a constant-returns-to-scale production technology (3) by supplying their own physical capital $k_{t}$, and labor effort $l_{t}$. The household's level of knowledge $h_{t}$ augments the productive capacity of each hour spent working, such that $h_{t} l_{t}$ represents the effective labor input for production.

The utility function (1) can be interpreted as the reduced form of one that incorporates home production. ${ }^{6}$ The presence of $h_{t}$ in both (1) and (3) implies that productivity in the home and productivity in the market increase at the same rate.

\footnotetext{
'In the past, other incentives have inchuded the investment tax credit for equipment purchases and the tax-favored treatment of capital gains. Both of these were repealed by the Tax Reform Act of 1986 .

${ }^{6}$ See (ireenwood, Rogerson, and Wright (1995).
} 
As a result, $l_{t}$ remains stationary along the model's balanced growth path. The parameters $B$ and $\gamma$ affect the supply of market labor, where $\frac{1}{\gamma-1}$ is the intertemporal elasticity of substitution in labor supply. As $\gamma$ becomes large, $l_{t}$ approaches 1.0 and the model reduces to one with a fixed supply of labor.

Investment adds to the stock of physical capital according to the law of motion (4), where $A_{1}$ and $\delta$ are parameters that govern the relationship between new investment and next period's capital stock. When $A_{1}=1$ and $\delta=1$, capital depreciates fully after one period, whereas $0<\delta<1$ implies that capital is long lasting. This nonlinear specification facilitates closed-form decision rules and can be viewed as reflecting adjustment costs as in Lucas and Prescott (1971). ${ }^{7}$

Following Arrow (1962) and Romer (1986), we assume that the mechanism for knowledge accumulation is learning by doing. This means that knowledge grows proportionally to, and as a by-product of, accumulated private investment and research activities. This idea can be captured by the specification $h_{t}=K_{t}$, where $K_{t}$ is the average stock of capital across households. The assumption that households view $h_{t}$ as outside of their control requires that there be a sufficiently large number of households so that no single household can affect the value of $K_{t}$. However, since all households are identical, $K_{t}=k_{t}$ in equilibrium. We therefore impose the condition $h_{t}=K_{t}=k_{t}$ after households make their optimal allocation decisions.

Equation (5) says that in deciding how much to earn and invest, households also determine their tax rate according to the function $F\left(y_{t}, i_{t}\right)$, which we specify more completely below.

\footnotetext{
${ }^{7}$ This specification has been used in applied work by Hercowitz and Sampson (1991), Kocherlakota and $\mathrm{Yi}$ (1994), and Cassou and Lansing (1995), among others. Our setup differs from the standard one given by: $k_{t+1}=-(1-\bar{\delta}) k_{t}+i_{l}$, where $\delta$ in the linear depreciation rate. Equation (4) can also be viewed as capturing the behavior of an aggregatestock that is measured by adding up different types of capital (structures, equipment, consumer durables, etc.) which each display different depreciation characteristics. Moreover, capital stcrk data compiled by the U.S, Department of Commerce in Fixed Reproducible Tangible Wealth in the Unaleri Stutes includes a "capital input" series. This alternative measure of the net stock emplows a depreciation schedule that is slower than straight line during the early years of an asset's life, but more rapid during later years.
} 


\subsection{The Tax System}

The tax function $F\left(y_{t}, i_{t}\right)$ is set by the government and is assumed to take the following form

$$
\tau_{t}=\bar{\tau}\left(\frac{y_{t}-\phi i_{t}-D_{t}}{Y_{t}-\phi I_{t}-D_{t}}\right)^{n}
$$

where $Y_{t}$ and $I_{t}$ are the average levels of income and investment in the economy, and $\bar{\tau} \in[0,1)$ and $n \geq 0$ are parameters that govern the level and progressivity of the tax schedule. As with $K_{t}$, households view the economy-wide averages as outside their control, and we impose the equilibrium conditions $Y_{t}=y_{t}$ and $I_{t}=i_{t}$ after decisions are made. When $n>0$, households with above average taxable income face a higher tax rate than those with below average taxable income. In contrast, when $n=0$, all households face the same tax rate $\bar{\tau}$ regardless of their taxable income. In our model, therefore, $n>0$ represents a progressive tax schedule, while $n=0$ represents a horizontal or "flat" tax schedule.

Since we do not consider a separate corporate income tax, our evaluation of a flat tax does not capture any benefits from eliminating the double taxation of capital income. Offsetting this, however, is the fact that the investment write-off in our model is applied to the personal tax schedule, which is more progressive than the corporate tax schedule. This tends to magnify the benefits of a larger write-off.

We also note that the investment write-off in our model applies to expenditures for both physical and human capital -- since there is nothing to differentiate the two in a learning-by-doing framework. In comparison. the Hall and Rabushka plan allows for the write-off of expenditures on physical capital, but not for private individuals' expenditures on education. To the extent that these education expenditures contribute to the stock of human capital. the Hall and Rabushka plan does not go far enough in defining the types of spending that glualify as investment. ${ }^{8}$ In this respect, our setup can be viewed as an idealized version of a flat tax in which all types of investment qualify for the write-olf.

The government sets the standard derduction $D_{t}$, which we model as a constant

"This is a point that is emphasized ly Judd (1996(i) 
fraction of average pre-tax income:

$$
D_{t}=\alpha Y_{t}
$$

where $\alpha \geq 0$. Since $D_{t}$ is a function of $Y_{t}$ (as opposed to $y_{t}$ ), households take this deduction as given.

As we shall see, the tax system in this model has an important influence on how much households consume, work, and invest. For our analysis, it will be useful to distinguish between the average tax rate and the marginal tax rate. The average tax rate is defined as taxes paid $T_{t}$ divided by the household's taxable income $y_{t}-\phi i_{t}-D_{t}$. The marginal tax rate is defined as the change in taxes paid divided by the change in taxable income, where we interpret "change" as an infinitesimally small amount. Intuitively, the marginal tax rate represents the rate applied to the last dollar earned. The expressions that govern the various tax rates are as follows:

$$
\begin{aligned}
& \text { Taxes paid }=T_{t}=\tau_{t}\left(y_{t}-\phi i_{t}-D_{t}\right)=\bar{\tau} \frac{\left(y_{t}-\phi i_{t}-D_{t}\right)^{n+1}}{\left(Y_{t}-\phi I_{t}-D_{t}\right)^{n}}, \\
& \text { Average tax rate }=\frac{T_{t}}{y_{t}-\phi i_{t}-D_{t}}=\tau_{t}, \\
& \text { Marginal tax rate }=\frac{\partial T_{t}}{\partial\left(y_{t}-\phi i_{t}-D_{t}\right)}=(n+1) \tau_{t} .
\end{aligned}
$$

In equilibrium, when $Y_{t}=y_{t}$ and $I_{t}=i_{t}$. we have $\tau_{t}=\bar{\tau}$, so that the average tax rate is $\bar{\tau}$ and the marginal tax ralc is $(n+i) \tau$. When $n>0$, the marginal tax rate is greater than the average tax rutc. Which implies that the tax schedule slopes up as a function of taxable incume. In cuntrast. When $n=0$. the two tax rates are the same, which implies that the tax scherinl. is flat. Moreover, when $n=0$ and $\phi=1$, a flat tax is equivalent to one that taxe (nnsimption at the rate $\tau_{c}=\frac{\tau}{1-\bar{\tau}} \cdot 9$

It is important to recomian that a llat tax can still exhibit features which are progressive. The crucial element that woverns the progressivity of a flat tax is the level of the standard deduction $/)_{t}$. Ti, see this, consider an alternative tax rate

\footnotetext{
${ }^{9}$ In this case, the equilibrium version of the houschold budget constraint (2) can be written as: $r_{t}+\tau_{c}\left(c_{t}-D_{t}\right)+i_{t}=y_{t}$. where $\left(r_{t}-I_{t}\right)$ represents taxable consumption expenditures.
} 
defined as taxes paid $T_{t}$ divided by pre-tax income $y_{t}$. Using equation (8) with $n=0$ we obtain

$$
\frac{T_{t}}{y_{t}}=\bar{\tau}\left(1-\frac{\phi i_{t}}{y_{t}}-\frac{D_{t}}{y_{t}}\right)
$$

If we assume that the standard deduction is held fixed at a specific dollar amount, say $\bar{D}$, for all tax payers (as is the case under the U.S. tax code), then the ratio $\frac{\bar{D}}{y_{t}}$ declines as income $y_{t}$ rises. If we further assume that the ratio $\frac{i_{t}}{y_{t}}$ remains constant, then equation (11) says that the tax rate $\frac{T_{t}}{y_{t}}$ will rise with income. In other words, households with higher incomes face higher tax rates-a feature that is progressive. ${ }^{10}$

In our model, the standard deduction is not held fixed, but instead rises with the average level of income, as given by (7). This formulation ensures that the standard deduction continues to represent a significant fraction of income in this growing economy. Substituting (7) into (11) yields $\frac{T_{t}}{y_{t}}=\bar{\tau}\left(1-\frac{\phi i_{t}}{y_{t}}-\frac{\alpha Y_{t}}{y_{t}}\right)$, which shows that households with above average incomes $\left(y_{t}>Y_{t}\right)$ continue to face higher tax rates than those with below average incomes $\left(y_{t}<Y_{t}\right)$, even when $n=0$ (again assuming that $\frac{i_{t}}{y_{t}}$ remains constant).

\subsection{Public Expenditures}

The government sets the tax code parameters $\bar{\tau}, n, \phi$, and $\alpha$ to finance a required level of per capita public expenditures $R_{t}$ which do not contribute to either production or household utility. ${ }^{11}$ We assume that the government balances its budget period-byperiod such that its budget constraint is given by

$$
R_{t}=\tau_{t}\left(Y_{t}-\phi I_{t}-D_{t}\right)
$$

Per capita public expenditures are assumed to increase in fixed proportion to the average level of income in the economy, such that $R_{t}=\psi Y_{t}$, where $\psi \geq 0$. Again, this formulation ensures that public cxpenditures remain a significant fraction of output as the cconomy grows.

\footnotetext{
${ }^{10}$ For more details on a progressive llat tax, see Hall and Rubushka (1995), chapter 3.

"Our growth computations remain unaffected if public expenditures enter the utility function (1) in an additively separable way.
} 


\section{Incentive Effects of the Tax System}

In this section, we show how the tax system affects household decisions and the economy's per capita growth rate.

\subsection{Household Decisions}

The household's first-order conditions with respect to the indicated variables are:

$$
\begin{aligned}
c_{t}: & \lambda_{t}=\left(c_{t}-B h_{t} l_{t}^{\gamma}\right)^{-1}, \\
l_{t}: & \lambda_{t}\left[1-(n+1) \tau_{t}\right]\left[\frac{(1-\theta) y_{t}}{l_{t}}\right]=B \gamma h_{t} l_{t}^{\gamma-1}\left(c_{t}-B h_{t} l_{t}^{\gamma}\right)^{-1}, \\
k_{t+1}: & \frac{\lambda_{t} i_{t}}{\delta k_{t+1}}\left[1-\phi(n+1) \tau_{t}\right]= \\
& \beta \lambda_{t+1}\left\{\frac{\theta y_{t+1}}{k_{t+1}}\left[1-(n+1) \tau_{t+1}\right]+\frac{(1-\delta) i_{t+1}}{\delta k_{t+1}}\left[1-\phi(n+1) \tau_{t+1}\right]\right\},
\end{aligned}
$$

where $\lambda_{t}$ is the Lagrange multiplier associated with the budget constraint (2). A convenient property of the utility function (1) is that $l_{t}$ can be solved for independently of the marginal utility of consumption $\lambda_{t}$. By combining (3), (13), and (14), and then imposing the equilibrium conditions $Y_{t}=y_{t}, I_{t}=i_{t}$, and $h_{t}=K_{t}=k_{t}$, we obtain the following optimal decision rule for household labor hours:

$$
l_{t}=\left\{\frac{A_{0}(1-\theta)}{B \gamma}[1-(n+1) \bar{\tau}]\right\}^{\frac{1}{\theta+\gamma-1}} .
$$

By substituting (16) into (3) and again imposing equilibrium, per capita income (or output) can be written as:

$$
y_{t}=\left\{A_{0}^{\gamma}\left(\frac{1-\theta}{B \gamma}\right)^{1 \cdot \theta}[1-(n+1) \bar{\tau}]^{1-\theta}\right\}^{\frac{1}{\theta+\gamma-1}} k_{t} .
$$

To obtain the optimal decision rules for household consumption and investment, we employ the method of undetermined coeflicients. First, we guess the following functional forms for $i_{t}$ and $\lambda_{t}$ :

$$
i_{t}=a_{0}\left[\frac{1-(n+1) \bar{\tau}}{1-\phi(n+1) \bar{\tau}}\right] y_{t}
$$




$$
\frac{1}{\lambda_{t}}=b_{0} y_{t}
$$

where $a_{0}$ and $b_{0}$ are constants to be determined and $y_{t}$ is given by (17). Substituting the conjectured forms into (15) and imposing equilibrium yields

$$
a_{0}=\frac{\theta \delta}{\rho+\delta}
$$

where $\rho \equiv \frac{1}{\beta}-1$ is the household's rate of time preference and $a_{0}$ can be interpreted as the marginal propensity to save out of after-tax income. Since $\frac{i_{t}}{y_{t}}$ is a constant, the analysis of section 2.2 indicates that our flat tax specification will continue to exhibit features which are progressive. The investment decision rule (18) can also be written as $i_{t}=a_{0}\left(1-\tau_{i}\right) y_{t}$, where $\tau_{i}$ is the effective tax rate on investment which is given by $\tau_{i}=\frac{(1-\phi)(n+1) \bar{\tau}}{1-\phi(n+1) \bar{\tau}}$. Notice that when $\phi=1$, we have $\tau_{i}=0$.

The next step is to verify that (19) is a correct guess by showing that $b_{0}$ is, in fact, a constant. To do this, we use (13) and (19) to obtain

$$
\begin{aligned}
c_{t} & =b_{0} y_{t}+B h_{t} l_{t}^{\gamma} \\
& =b_{0} y_{t}+\frac{1-\theta}{\gamma}[1-(n+1) \bar{\tau}] y_{t}
\end{aligned}
$$

where the second equality replaces $B h_{t} l_{t}^{\gamma}$ by an equivalent expression that is obtained by combining (13) and (14). Substituting (7), (18), and (21) into the household budget constraint (2) yields

$$
b_{0}=1-\bar{\tau}-a_{0}(1-\phi \bar{\tau})\left[\frac{1-(n+1) \bar{\tau}}{1-\phi(n+1) \bar{\tau}}\right]+\bar{\tau} \alpha-\frac{1-\theta}{\gamma}[1-(n+1) \bar{\tau}]
$$

which is a constant and thus verifies our original guess. Finally, substituting the expression for $b_{0}$ back into (21) yields

$$
c_{t}=\left\{1-\bar{\tau}-a_{0}(1-\phi \tau)\left[\frac{1-(n+1) \bar{\tau}}{1-\phi(n+1) \bar{\tau}}\right]+\bar{\tau} \alpha\right\} y_{t}
$$

where the coefficient on $y_{t}$ can be interpreted as the household's marginal propensity to consume.

The decision rules for $l_{t}, y_{t}, i_{t}$, and $c_{t}$ illustrate some important points regarding the incentive effects of the tax system. Notice that all of these decision rules depend on the slope parameter $n$, which controls the progressivity of the tax schedule. For 
a given value of $\bar{\tau}$, equation (16) says that a reduction in $n$ (which makes the tax schedule flatter) will lead to an increase in labor hours. ${ }^{12}$ Since labor hours are used to produce goods which are sold in the market, equation (17) says that per capita income will also rise. A reduction in $n$ leads to higher investment in two ways: by lowering the effective tax rate $\tau_{i}$, and by increasing $y_{t}$. Equation (23) shows that the immediate effect of a reduction in $n$ on consumption is ambiguous: there is a positive effect due to the increase in $y_{t}$, but a negative effect due to the lower marginal propensity to consume.

In general, the immediate effect of larger write-off fraction $\phi$ is to raise investment and lower consumption. ${ }^{13}$ Neither labor hours, income, or investment are affected by the parameter $\alpha$, which determines the level of the standard deduction $D_{t}$. In contrast, household consumption depends positively on $\alpha$.

In equilibrium, the term $\tau_{t} D_{t}$ in the household budget constraint can be written as $\bar{\tau} \alpha y_{t}$. This term can be interpreted as tax revenues which are returned to households in the form of lump-sum transfers. Equation (23) shows that these transfers are wholly consumed.

\subsection{The Per Capita Growth Rate}

We now use the above results to show how the tax system influences economic growth in our model. A simple expression for the economy's per capita growth rate $g$ can be obtained by substituting the decision rules for $y_{t}$ and $i_{t},(17)$ and (18), into the law of motion (4), and taking logarithms to obtain

$$
\begin{aligned}
g=\ln \frac{k_{t+1}}{k_{t}} & =\ln \frac{y_{t+1}}{y_{t}}=\ln \frac{c_{t+1}}{c_{t}}=\ln \left[A_{0}^{\frac{\delta \gamma}{\theta+\gamma-1}} A_{1} a_{0}^{\delta}\left(\frac{1-\theta}{B_{\gamma}}\right)^{\frac{(1-\theta) \delta}{\theta+\gamma-1}}\right]+ \\
& \left(\frac{\delta \gamma}{\theta+\gamma-1}\right) \ln |1-(n+1) \tau|-\delta \ln [1-\phi(n+1) \bar{\tau}] .
\end{aligned}
$$

Notice that $g$ is constant over time. which implies that the economy is always in a

\footnotetext{
larhis result can be formally prowed by rxamining the sign of the derivitive $\frac{\partial l_{s}}{\partial n}=$ $\frac{\gamma}{(A+\gamma 1) !(n+1) \tau} l_{t}$. Since $\gamma>1$, we know that $\theta+\gamma-1>0$. Then if $0<(n+1) \bar{\tau}<1$, we have $\frac{\partial l_{1}}{\partial q_{2}}<0$.

${ }^{13}$ It can be shown that when $n>0$ and $0<(n+1) \tau<1$, we have $\frac{\partial i_{s}}{\partial \phi}>0$ and $\frac{\partial c_{f}}{\partial \phi}<0$.
} 
condition of balanced growth, i.e., our model exhibits no transition dynamics. ${ }^{14}$ The growth effects of the individual tax code parameters $\bar{\tau}, n$, and $\phi$ are described by the following derivatives:

$$
\begin{aligned}
& \frac{\partial g}{\partial \bar{\tau}}=\frac{-\delta(n+1)}{(\theta+\gamma-1)}\left\{\frac{(1-\phi) \gamma+\phi(1-\theta)[1-(n+1) \bar{\tau}]}{[1-(n+1) \bar{\tau}][1-\phi(n+1) \bar{\tau}]}\right\}<0, \\
& \frac{\partial g}{\partial n}=\frac{-\delta \bar{\tau}}{(\theta+\gamma-1)}\left\{\frac{(1-\phi) \gamma+\phi(1-\theta)[1-(n+1) \bar{\tau}]}{[1-(n+1) \bar{\tau}][1-\phi(n+1) \bar{\tau}]}\right\}<0, \\
& \frac{\partial g}{\partial \phi}=\frac{\delta(n+1) \bar{\tau}}{1-\phi(n+1) \bar{\tau}}>0
\end{aligned}
$$

where the signs of the derivatives are based on the assumption that $\phi \in[0,1]$ and $0<(n+1) \bar{\tau}<1$. Holding everything else constant, equation (26) tells us that a reform that makes the tax schedule flatter will reduce the slope parameter $n$ and thereby increase growth. Equation (27) shows that a more generous write-off fraction $\phi$ will also increase growth. The flat tax proposal of Hall and Rabushka $(1985,1995)$ incorporates both of these changes. Notice that the magnitude of the growth effects are influenced by the parameters $\gamma, 0$. and $\delta$. The parameter $\gamma$ controls the elasticity of household labor supply: $\theta$ is capital's share of output, and $\delta$ is the elasticity of the capital stock with respect to new investment.

An increase in either $\gamma$ or $\theta$ will cause $\frac{\partial y}{\partial m}$ to become weaker, but will have no effect on $\frac{\partial g}{\partial \phi}$. An increase in $\delta$ will cause buth $\frac{\partial g}{\partial h_{2}}$ and $\frac{\partial g}{\partial b^{6}}$ to become stronger. ${ }^{15}$ The intuition for these results is straight forward. A larger value of $\gamma$ implies that household labor supply is less sensitive tw changen in the after-tax wage. A larger value of $\theta$ reduces the contribution of the labur input to production. Thus, both parameters impact growth via the labor hums chammel. In contrast. $\delta$ influences growth through the investment channel. A larger value of $\delta$ means that households devote more of their income to investment instead of lw consumption. This magnifies the impact of tax

\footnotetext{
${ }^{14}$ This is a general characteristic of remlenerfoum grometh models with a production technology that is linear in $k_{\ell}$. See Barro and Sala-i-Matum (lous), ( hatuter 4.

${ }^{15}$ Formally; this can $l \times$ shown $b$ exammung the signn of the second derivitives $\frac{\partial}{\partial p_{i}}\left|\frac{\partial g}{\partial n}\right|$ and $\frac{\partial}{\partial p_{1}}\left|\frac{\partial g}{\partial \phi}\right|$. where $\mid$ represents almilute value and $p_{\mathbf{2}} \quad\{\gamma, \theta, \delta\}$. A positive (negative) second derivitive implies that an increase in the parameter will cause the growth effect to become stronger (weaker).
} 
reforms that affect investment incentives.

It can also be shown that $\frac{\partial g}{\partial \phi}$ becomes stronger as $n$ increases. This means that a more generous write-off produces larger growth gains when applied to a steeper tax schedule.

\subsection{Revenue Neutrality}

The flat tax proposal of Hall and Rabushka is designed to be "revenue neutral." The intent of the plan is to improve economic efficiency while leaving aside arguments about the appropriate size of government. Since tax reforms in our model affect the trend growth of all variables, the concept of revenue neutrality used here is necessarily a relative one. Specifically, we hold tax revenues constant relative to the size of the economy. Given that tax revenues must finance public expenditures according to $R_{t}=\psi y_{t}$, revenue neutrality requires that $\psi$ remain unchanged as tax code parameters are varied. By substituting equations (6), (7), and (18) into (12) and imposing equilibrium, we obtain the following relationship among the tax code parameters:

$$
\psi^{\prime}=\bar{\tau}\left\{1-o a_{0}\left[\frac{1-(n+1) \bar{\tau}}{1-\phi(n+1) \bar{\tau}}\right]-\alpha\right\} .
$$

In our experiments, a particular tax reform may cause $n, \phi$, and $\alpha$ to change. Revenue neutrality is maintained by adjusting $\bar{\tau}$ under the new system so that (28) is satisfied at the pre-reform value of $2,{ }^{16}$ In general; adopting a flat tax requires a higher post-reform value of $\dot{\tau}$ to pay for the more generous write-off and deduction features. Since $\frac{\partial y}{\partial \tau}<0$ from equation $(2 \overline{5})$, a higher value of $\bar{\tau}$ mitigates the resulting growth benefits.

In the remaining sections of the paper. we undertake a quantitative evaluation of a flat tax in a calibrated version if the model.

\section{Calibration}

Parameters are assigned values based on empirically observed features of the U.S. economy. For parameters that are important to the results, a range of values is

\footnotetext{
${ }^{16}$ Due to the presence of an investment tax Laffer curve, there are actually two values of $\bar{\tau}$ that satisfy this requirement. We pick the smaller of the two in our quantitative experiments.
} 
examined.

A time period in the model is taken to be one year. The tax code parameters $\bar{\tau}$ and $n$ are estimated from the 1994 U.S. tax schedule for married taxpayers filing jointly. Figure 1 shows that there are five different marginal tax rates, ranging from 15 to 39.6 percent. These marginal tax rates are used to construct an average rate schedule, which is also shown in figure $1 .^{17}$

In figure 2, we plot the U.S. average tax rate versus the "income ratio," which we define as taxable income divided by its mean level. This ratio represents the empirical counterpart of the quantity $\frac{y_{t}-\phi i_{t}-D_{t}}{Y_{t}-\phi I_{t}-D_{t}}$ in our model. In constructing figure 2 , we use a mean taxable income of $\$ 40,000$. This number is based on tax return data from 1992 (the most recent available). ${ }^{18}$ A nonlinear least squares regression of the average tax rate on the corresponding income ratio yields the following relationship:

$$
\text { Average Tax Rate }=0.1823 \text { (Income Ratio) }{ }^{0.2734}
$$

Comparing the above expression to equation (6) yields $\bar{\tau}=0.1823$ and $n=$ $0.2734 .{ }^{19}$ Figure 2 shows that the fitted relationship is flatter than the U.S. tax schedule for income ratios between about 1.0 and 2.0, but steeper for income ratios that fall into the lowest tax bracket. For the mean level of taxable income, the income ratio is exactly 1.0 and the fitted relationship underestimates the progressivity of the I.S. tax schedule. This suggests that our calibration procedure yields a conservative estimate of the growth benefits of adopting a flat tax.

The tax code parameter $a$ is calibrated by dividing the total dollar amount of

\footnotetext{
${ }^{17}$ For each level of income, the average tax rate is defined as total tax payments divided by total taxable income. For example, a married couple whose total taxable income is $\$ 100,000$ would pay 15 percent on the first $\$ 38,000$ of their income, 28 percent on the next $\$ 53,850$, and 31 percent on the remaining $\$ 8,150$. This adds up to a total tax payment of $\$ 23,304.50$, which corresponds to an average tax rate of 23.3 percent $\left(=\frac{\$ 23.3(4.50}{\$ 10(1),(\%)} \times 100\right)$.

${ }^{18}$ There were $41,577,964$ joint returns filed in 1992, which accounted for a total taxable income of $\$ 1,653,210,099,000$. Dividing the second number by the first yields a mean taxable income across all joint returns of $\$ 39,762$. See U.S. Internal Revenue Scrvice, Statistics of Income Bulletin, volume 15, Summer 1995, table 3, p. 77.

${ }^{19}$ Couveia and Strauss (1994) estimate U.S. average tax rates from 1979 to 1989 using a functional form that employs three parametcrs: Average Tax Ratc $=b\left\{1-\mid s(\text { Economic Income })^{p}+\left.1\right|^{\frac{-1}{\mu}}\right\}$, where "Economic Income" is expressed in thousands of dollars. In our model, this specification would cause the asymptotic average and marginal tax rates to both equal $b$, since household income grows over time.
} 
standard deductions taken in 1992 by GDP. This yields $\alpha=0.06 .{ }^{20}$ The writeoff fraction $\phi$ is chosen such that the magnitude of the investment write-off $\tau_{t} \phi i_{i}$ coincides with the value of a standard capital depreciation allowance $\tau_{t} \hat{\delta} k_{t}$, where we take $\hat{\delta}=0.07$. Given our target values of $\frac{k_{t}}{y_{t}}=2.6$ and $\frac{i_{t}}{y_{t}}=0.22$ (described below), we obtain $\phi=0.07\left(\frac{k_{t} / y_{t}}{i_{t} / y_{t}}\right)=0.8273$.

Substituting the above values for $\bar{\tau}, n, \alpha$, and $\phi$ into equation (28) yields $\psi=$ 0.1382 . This means that tax revenues represent about 13.8 percent of output in our model. Also with these values, we have $\tau_{i}=\frac{(1-\phi)(n+1) \tau}{1-\phi(n+1) \bar{\tau}}=0.0496$, which shows that the effective tax rate that governs the investment/saving decision under our calibration is very low. This is probably a reasonable portrayal of current U.S. tax law because a large fraction of U.S. savings is done through vehicles like pensions, Individual Retirement Accounts (IRAs), and 401k plans, which already receive consumption tax treatment. ${ }^{21}$

Following Greenwood, Hercowitz, and Huffman (1988), we choose $\gamma=1.60$ as our baseline value, which implies that the intertemporal elasticity of substitution in labor supply $\frac{1}{\gamma-1}$ is equal to 1.7. As noted by these authors, this value lies about midway in the range of the empirical elasticity estimates. We set capital's share of output equal to $\theta=0.36$, which is within the range estimated by Christiano (1988). Later, in our sensitivity analysis, we will examine the effects of varying both $\gamma$ and $\theta$.

Given the parameter values noted above, we simultaneously pick the remaining five parameters $A_{0}, A_{1}, \delta, B$, and $\beta$ so that the model's balanced growth path displays five characteristics identified from long-run U.S. data. The first characteristic is the economy's per capita growth rate which is set at 1.80 percent in order to coincide with the postwar ('.S. average. The second and third characteristics are the capital-output ratio $\frac{k_{t}}{y_{t}}$ and the investment-output ratio $\frac{z_{t}}{y_{t}}$. We choose $\frac{k_{t}}{y_{t}}=2.6$ and $\frac{i_{t}}{y_{t}}=0.22$, again, to coincide with postwar :S. averages. ${ }^{22}$ The fourth characteristic is labor supply.

\footnotetext{
2"In 1992 , Lotal standard deductions were $\$ 366.5$ billion and nominal GDP was $\$ 6202$ billion. See U.S. Internal Revenue Service, Statistess of Income Bulletith volume 15, Summer 1995, table 7, p. 160, and Economic Report of the Prestdent 1995, table B-1, p. 274.

${ }^{21}$ Wr arknuwledge Bill Gale and hen Judd for making this point.

${ }^{22}$ The sample period is 1954 to 1992 . The series for $k_{t}$ and $i_{t}$ include business equipment and structures, consumer durables, and residential components, in 1987 dollars, from Fixed Reproducible Tangble Wealth in the United States, U.S. Department of Commerce (1993). The "capital input"
} 
Given a time endowment normalized to one, we choose $l=0.30$, which implies that households spend about one-third of their discretionary time in market work. The fifth characteristic is the real after-tax interest rate. ${ }^{23}$ We identify two values that are of particular interest. One is 6.9 percent, which is the value estimated by Cooley and Prescott (1995) using data from the U.S. National Income and Product Accounts. The other is 4.0 percent, which is a value commonly used in macroeconomic research. Table 1 summarizes the baseline parameter values that we obtain using the above methodology.

Table 1: Baseline Parameter Values

\begin{tabular}{ccc}
\hline \hline & \multicolumn{2}{c}{ After-Tax Interest Rate } \\
\cline { 2 - 3 } Parameter & $6.9 \%$ & $4.0 \%$ \\
\hline $\bar{\tau}$ & 0.1823 & 0.1823 \\
$n$ & 0.2734 & 0.2734 \\
$\alpha$ & 0.0600 & 0.0600 \\
$\phi$ & 0.8273 & 0.8273 \\
$\psi$ & 0.1382 & 0.1382 \\
$\theta$ & 0.3600 & 0.3600 \\
$\gamma$ & 1.6000 & 1.6000 \\
$A_{0}$ & 0.8311 & 0.8311 \\
$A_{1}$ & 1.2714 & 1.1201 \\
$\delta$ & 0.0899 & 0.0386 \\
$B$ & 0.8109 & 0.8109 \\
$\beta$ & 0.9524 & 0.9790 \\
\hline
\end{tabular}

Notice that $\delta$ is significantly higher when we calibrate to an after-tax interest rate of 6.9 percent. As discussed in section 3.2 , this means that the growth effects $\frac{\partial g}{\partial n}$ and $\frac{\partial g}{\partial \phi}$ will be stronger under this calibration.

\section{Quantitative Results}

Figures 3 through 7 summarize the results of our quantitative experiments. To construct these figures, we use equation (24) to compute the growth rate under a progressive tax system and various versions of a flat tax system. On the vertical axis of each figure, we plot the difference in growth rates $\Delta g$, where $\Delta g$ measures the version of the net stock series was used for the capital data (see footnote 6). The data for $y_{t}$ is obtained from the Citibase series GNPQ.

${ }^{23}$ The after-tax interest rate $\hat{r}$ is defined by introducing privately issued real bonds (which exist in zoro net supply) into equation (2). The first order condition for bonds gives $\hat{r}=\exp (g-\ln \beta)-1$. 
increase in growth that occurs when switching from a progressive tax system to a revenue neutral flat tax. Given our use of logarithms to define $g$, the first term in equation (24) has no effect on the magnitude of $\Delta g$.

In most of our experiments, a flat tax is defined by $n=0$ and $\phi=1$, consistent with the proposal of Hall and Rabushka. However, in one experiment (figure 5), a flat tax is defined by $n=0$ and $\phi=0.8273$, i.e., there is no change in the investment write-off. The purpose of this exercise to identify the growth gains attributable to changes in $n$ versus changes in $\phi$.

The standard deduction parameter is held fixed at $\alpha=0.06$ for all tax systems except in one experiment (figure 6), where we allow the deduction under the flat tax to vary over a wide range. This is done to examine the impact of a reform that combines a lower marginal tax rate with a more generous standard deduction. Most flat tax plans, including the proposal of Hall and Rabushka, incorporate a larger deduction to provide features of progressivity and to limit the burden of taxes on the poor.

In all of our experiments, we consider three different values of the parameter $\gamma$. Recall that $\gamma$ controls the intertemporal elasticity of household labor supply. We consider the values $\gamma=\{1.333,1.6,6.0\}$, which correspond to elasticities of $\frac{1}{\gamma-1}=\{3.0,1.7,0.2\}$, respectively. This range spans the vast majority of elasticity estimates obtained from empirical studies. ${ }^{24}$ For each value of $\gamma$, we calibrate the other parameters to match the long-run characteristics of U.S. data, as described in section 4 .

In figure 3 , we plot $\Delta g$ versus $n$ for the three values of $\gamma$ noted above. At the far left of the figure, we have $n=0$ which implies that $\Delta g$ is due solely to the change in the write-off parameter 0 . At this point. implementing a full investment write-off raises growth by about 0.25 percentage points. Recall from section 3.2 , however, that a more generous write-off protuces larger gains as $n$ increases. Moreover, as $n$ increases, the progressive tax scherhlo becomes steeper and the gains from setting $n=0$ also become larger.

\footnotetext{
${ }^{24}$ See Mulligan (1995) for a review and summary of the various studies.
} 
When $n=0.2734$, the progressive tax in our model matches the steepness of the U.S. federal tax schedule. At this point, with $\bar{\tau}=0.1823$, the marginal tax rate is given by $(n+1) \bar{\tau}=0.2321$. From equation (28), a flat tax with $n=0, \phi=1$, and $\alpha=0.06$ requires a post-reform value of $\bar{\tau}=0.1950$ to maintain revenue neutrality. Thus, a flat tax results in a lower marginal tax rate, but requires a higher average tax rate to pay for the more generous investment write-off.

Figure 3 shows that when $n=0.2734$, the annual growth gain is between 0.509 and 0.850 percentage points, depending on the value of $\gamma$. A larger $\gamma$ implies a smaller growth gain. This confirms the analysis of section 3.2. A larger $\gamma$ means that labor supply is less sensitive to changes in the after-tax wage, which makes $\frac{\partial g}{\partial n}$ weaker. In switching to a flat tax, labor hours increase by only 0.9 percent (from 0.3 to 0.3027 ) when $\gamma=6$, but increase by 7.0 percent (from 0.3 to 0.3211 ) when $\gamma=1.333$. These results also confirm the findings of Stokey and Rebelo (1995) and Milesi-Ferretti and Roubini (1995) who show that the growth effects of distortionary taxation are sensitive to assumptions about the elasticity of household labor supply.

For the baseline value of $\gamma=1.6$, the model predicts that a flat tax will increase growth by 0.74 percentage points per year (from 1.80 percent to 2.54 percent). This figure implies enormous gains in output and welfare over time. For example, a growth rate of 1.80 percent will cause GDP per capita to doubie in 38.9 years, whereas a grow th rate of 2.54 percent will cause GDP to double in only 27.6 years. In terms of welfare, this translates into a 10.3 percent increase in household consumption each period-forever. ${ }^{25}$

Figure 4 show's that the growth gains are substantially smaller when the model is calibrated to an after-tax interest rate of 4.0 percent. The gains are now between 0.218 and 0.365 percentage points. A lower interest rate implies a smaller value of $\delta$

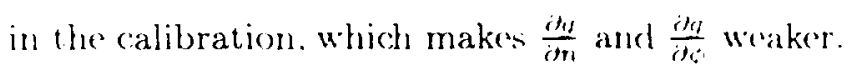

\footnotetext{
${ }^{25}$ From (1) and (2!), the household's value function is given by $V\left(k_{0}\right)=\sum_{t=0}^{\infty} \beta^{t} \ln \left(b_{0} y_{t}\right)$. Using (17), (22), and (24), the value furction can also be written as $V\left(k_{0}\right)=\frac{\ln d 0}{(1-\beta)}+$

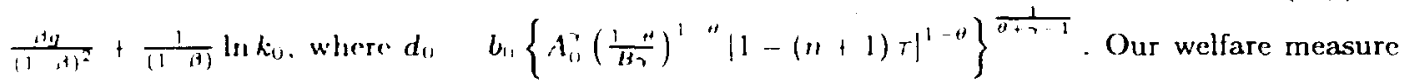
is $\left.100\left\{\exp _{1} \mid \Delta l^{\prime}(1-1)\right\}-1\right\}$. where $\mathrm{Jl}$ ' is the increase in lifetime utility that occurs when adopting a flat lax. Since the initial capital stek enters the expression for $V^{\prime}\left(k_{0}\right)$ in an additively separable way, the value of $k_{1}$ does not affect our welfare computation.
} 
In figure 5, we hold the write-off parameter fixed at $\phi=0.8273$ and compute the gains attributable solely to a change in the slope parameter $n$. At the far left of figure 5 , we have $\Delta g=0$, since both tax systems are now identical when $n=0$. When $n=0.2734$, the gains are between 0.183 and 0.633 percentage points. When $\gamma=1.6$, we have $\Delta g=0.49$. Comparing this result to the value of $\Delta g=0.74$ obtained earlier from figure 3 shows that both features of a flat tax-the lower marginal tax rate and the full investment write-off-are important contributors to the growth gain. The lower marginal tax rate accounts for about two-thirds of the gain, while the full write-off accounts for one-third.

In figure 6, we vary the standard deduction under a flat tax over a wide range. For this experiment, the model is calibrated to an after-tax interest rate of 6.9 percent and $n=0.2734$. We plot $\Delta g$ versus the ratio $\frac{\alpha_{f}}{\alpha_{p}}$, where $\alpha_{f}$ and $\alpha_{p}$ denote the standard deduction parameters under a flat tax and a progressive tax, respectively. We hold $\alpha_{p}$ fixed at 0.06 and allow $\alpha_{f}$ to vary from 0 to 0.18 . As the ratio $\frac{\alpha_{f}}{\alpha_{p}}$ increases, the growth gains become smaller because revenue neutrality requires a higher post-reform tax rate. At the far right when $\frac{\alpha_{f}}{a_{p}}=3$, the post-reform tax rate is $\bar{\tau}=0.2348$. At this point, with $\gamma=1.6$, the model predicts a growth gain of 0.437 percentage points. Thus, the desired features of progressivity that are achieved through a more generous standard deduction come at the cost of sacrificed growth gains.

Finally, figure i plots $\Delta g$ as a function of capital's share of output $\theta$. Again, the model is calibrated to an after-tax interest rate of 6.9 percent and $n=0.2734$. As $\theta$ increases, the contribution of the labor input to production becomes smaller, and the gains from adopting a flat lix are reduced. When $\theta=1.0$, the link between labor hours and gromth is complelely coliminated and a flat tax stimulates growth only through the investment chammel. In this case, the model predicts a growth gain of 0.458 percentage points

The experiment depicted in finure 7 provides information about how our model would perform under an alternatiw specification of the human capital technology. Our formulation implies that humelwhls underinvest in human capital relative to the socially optimal level because the ir decisinns do not take into account the learning by 
doing externality. As $\theta$ approaches 1.0, this externality is eliminated, but the growth gain remains significant at 0.458 percentage points. Thus, we believe our results are reasonably robust to alternative mechanisms for accumulating human capital.

\section{Conclusion}

This paper developed a simple theoretical framework to assess the growth effects of a flat tax. The model captures the incentive effects of rising marginal tax rates on household decisions to consume, work, and invest. These decisions, in turn, determine the rate of economic growth. Our model predicts that a revenue neutral flat tax can permanently increase per capita growth by 0.18 to 0.85 percentage points per year relative to a progressive system calibrated to match features of the U.S. federal tax schedule.

While our model is admittedly an abstract and simplified representation of the vastly complex U.S. tax code, we believe it provides some useful insight into the potential benefits of currently proposed tax reforms. By imposing the discipline of general equilibrium and revenue neutrality, we have attempted to take into account the macroeconomic repercussions that are likely to be induced by a major overhaul of the U.S. tax system. We expect that the model characteristics we identify as important for determining the strength of the growth gain will also be present in more complicated models. A more comprehensive analysis would need to explicitly address the distributional consequences of a flat tax, since its political feasibility depends crucially on perceptions of fairness and equal sacrifice. ${ }^{26}$

\footnotetext{
2"Sec Altig and Carlstrom (1995) and Ventura (1996) for analyses of the distributional consequences of tax reform in life-cycle moxlels.
} 


\section{References}

[1] Altig, David and Charles T. Carlstrom. (1995). "Marginal Tax Rates and Income Inequality: A Quantitative-Theoretic Analysis," Federal Reserve Bank of Cleveland, Working Paper No. 9508.

[2] Arrow, Kenneth J. (1962). "The Economic Implications of Learning by Doing," Review of Economic Studies, 29, 155-173.

[3] Barro, Robert J. and Xavier Sala-i-Martin. (1995). Economic Growth, New York: McGraw-Hill.

[4] Cassou, Steven P. and Kevin J. Lansing (1995). "Optimal Fiscal Policy, Public Capital, and the Productivity Slowdown," Federal Reserve Bank of Cleveland, Working Paper No. 9509.

[5] Christiano, Lawrence J. (1988). "Why Does Inventory Investment Fluctuate So Much?," Journal of Monetary Economics, 21, 247-280.

[6] Cooley, Thomas F. and Edward C. Prescott. (1995). "Economic Growth and Business Cycles," in.T. F. Cooley, ed., Frontiers of Business Cycle Research. Princeton, NJ: Princeton University Press.

[7] Devereux, Michael B. and David R.F. Love. (1994). "The Effects of Factor Taxation in a Two-Sector Model of Endogenous Growth," Canadian Journal of Economics, 27, 509-536.

[8] Glomm, Gerhard and B. Ravikumar. (1996). "Flat-Rate Taxes, Government Spending on Education and Growth," University of Virginia, Discussion Paper 269.

[9] Gouveia, Miguel and Robert P. Strauss. (1994). "Effective Federal Individual Income Tax Functions: An Exploratory Analysis," National Tax Journal 47, $317-339$.

[10] Greenwood, Jeremy, Zvi Hercowitz. and Gregory W. Huffman. (1988). "Investment. Capacity Ltilization, and the Real Business Cycle," American Economic Review, 78, 402-417.

[11] Greenwood. Jeremy, Richard Rogerson, and Randall Wright. (1995). "Household Production in Real Business Cycle Theory," in T. F. Cooley, ed., Frontiers of Business Cycle Research. Princeton. NJ: Princeton University Press.

[12] Hall. Robert E. and Alvin Rabushka. (1985). The Flat Tax. Stanford, CA: Hoover Institution Press.

[13] and (1995). The Flat Tax, Second Edition Stanford, CA: Inover Institution Press.

[1.1) Hercowitz, Zvi, and Michael Sampson. (1991). "Output Growth, the Real Wage, and Employment Fluctuations." American Economic Review. 81, 1215-1237.

[15] Ireland. Peter X. (1991). "Two Perspectives on Growth and Taxes," Federal Reserve Bank of Richmond. Eronomic Quarterly, 80, 1-17.

[16] Judd. Kenneth L. (1996). "Comments on Tax Reform." Hoover Institution, uripublished manuscript. 
[17] Jones, Larry E., Rodolfo Manuelli, and Peter E. Rossi. (1993). "Optimal Taxation in Models of Endogenous Growth," Journal of Political Economy, 101, 485-517.

[18] King, Robert G. and Sergio Rebelo. (1990). "Public Policy and Economic Growth: Developing Neoclassical Implications," Jourmal of Political Economy, 98, S127-S150.

[19] Kocherlakota, Narayana R. and Kei-Mu Yi. (1994). "Is There Endogenous Long Run Growth? Evidence from the U.S. and U.K." unpublished manuscript.

[20] Lucas, Robert E., Jr. (1990). "Supply-Side Economics: An Analytical Review," Oxford Economic Papers, 42, 293-316.

[21] _ and Edward C. Prescott. (1971). "Investment Under Uncertainty," Econometrica, 39, 659-681.

[22] Milesi-Ferretti, Gian Maria and Nouriel Roubini. (1995). "Growth Effects of Income and Consumption Taxes: Positive and Normative Analysis," International Monetary Fund, Working Paper 95/62.

[23] Miller, Preston J. (1984). "Income Stability and Economic Efficiency Under Alternative Tax Schemes," Carnegie-Rochester Conference Series on Public Policy, $20,121-142$.

[24] Mulligan, Casey B. (1995). "The Intertemporal Substitution of Work - What Does the Evidence Say?" University of Chicago, unpublished manuscript.

[25] Pecorino, Paul. (1993). "Tax Structure and Growth in a Model with Human Capital," Journal of Public Economics, 52, 251-271.

[26] . (1994). "The Growth Rate Effects of Tax Reform," Oxford Economic Papers, 46, 492-501.

[27] Rebelo, Sergio. (1991). "Long-Run Policy Analysis and Long-Run Growth," Journal of Political Economy, 99, 500-521.

[28] Romer, Paul. (1986). "Increasing Returns and Long-Run Growth," Journal of Political Economy. 94, 1002-1037.

[29] Stokey, Nancy L. and Sergio Rebelo (1995). "Growth Effects of Flat-Rate Taxes," Journal of Political Economy, 103, 519-550.

[30] Ventura. Gustavo. (1996). "Flat Tax Reform: A Quantitative Exploration," University of Illinois, ninpublished manuscript. 
Figure 1

U.S. TAX SCHEDULE FOR 1994

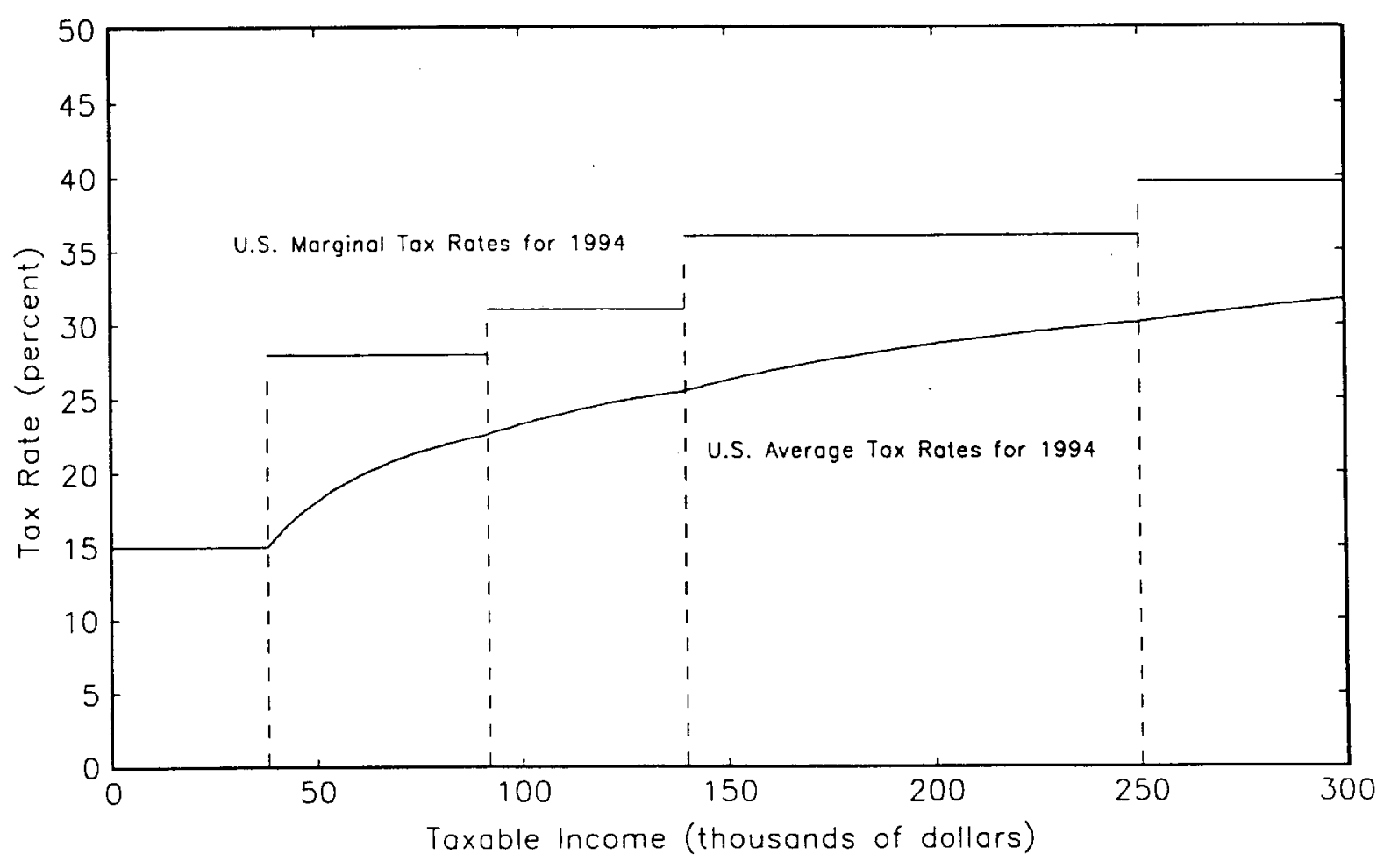

Figure 2

U.S. AVERAGE TAX RATES

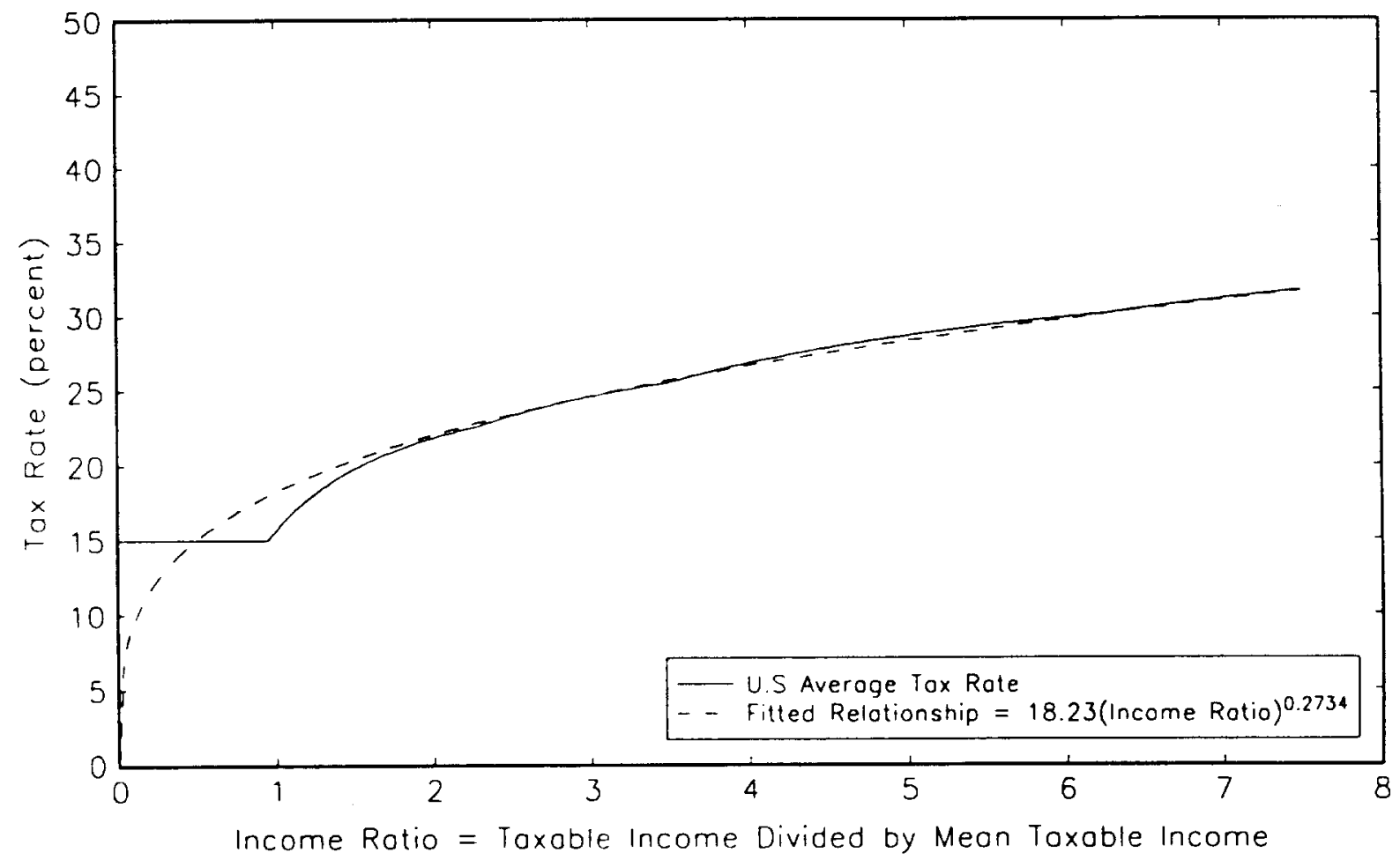


Figure 3

\section{DIFFERENCE IN GROWTH RATES: FLAT vS PROGRESSIVE TAX SYSTEM}

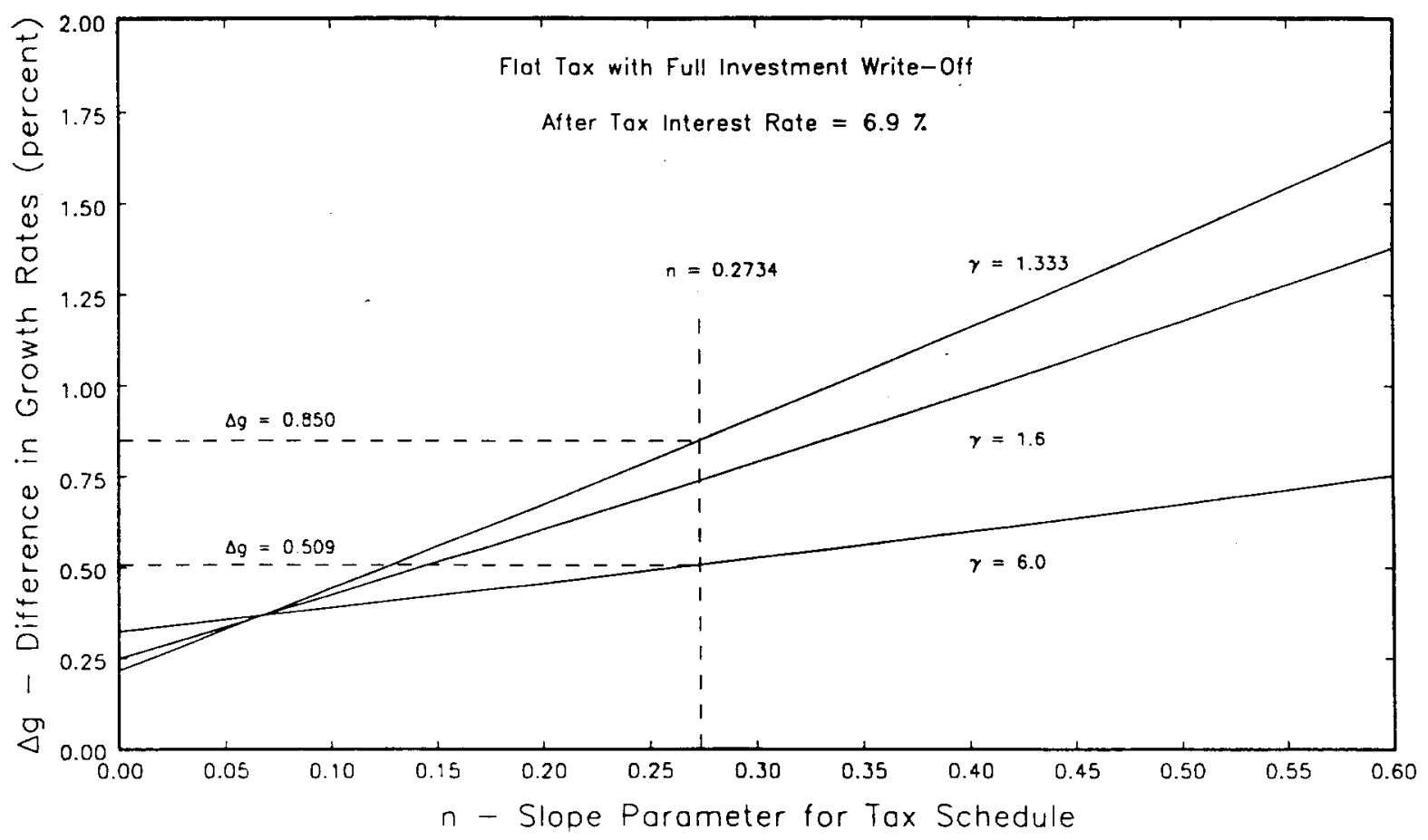

Figure 4

DIFFERENCE IN GROWTH RATES: FLAT VS PROGRESSIVE TAX SYSTEM

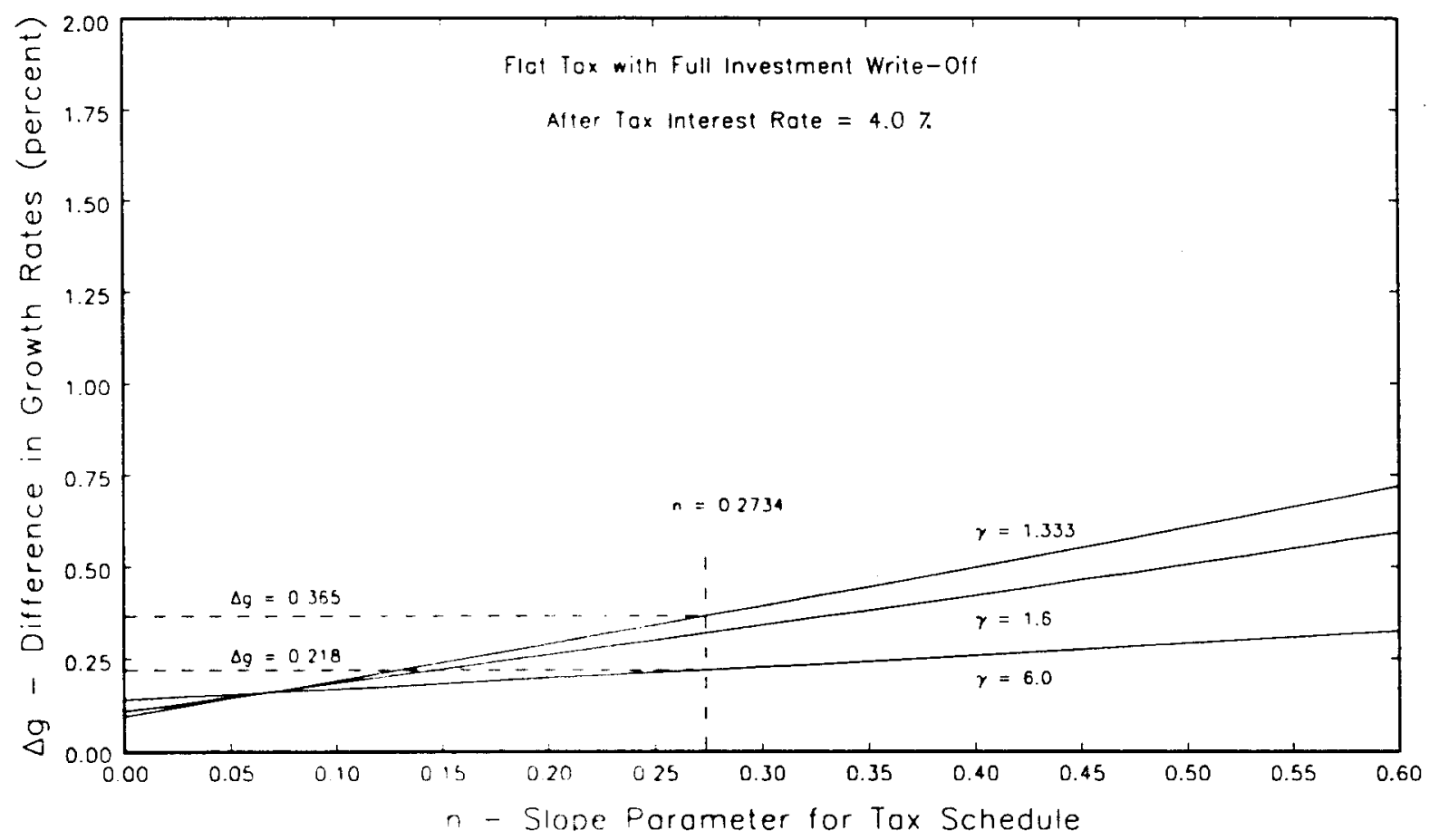


Figure 5

DIFFERENCE IN GROWTH RATES: FLAT vS PROGRESSIVE TAX SYSTEM

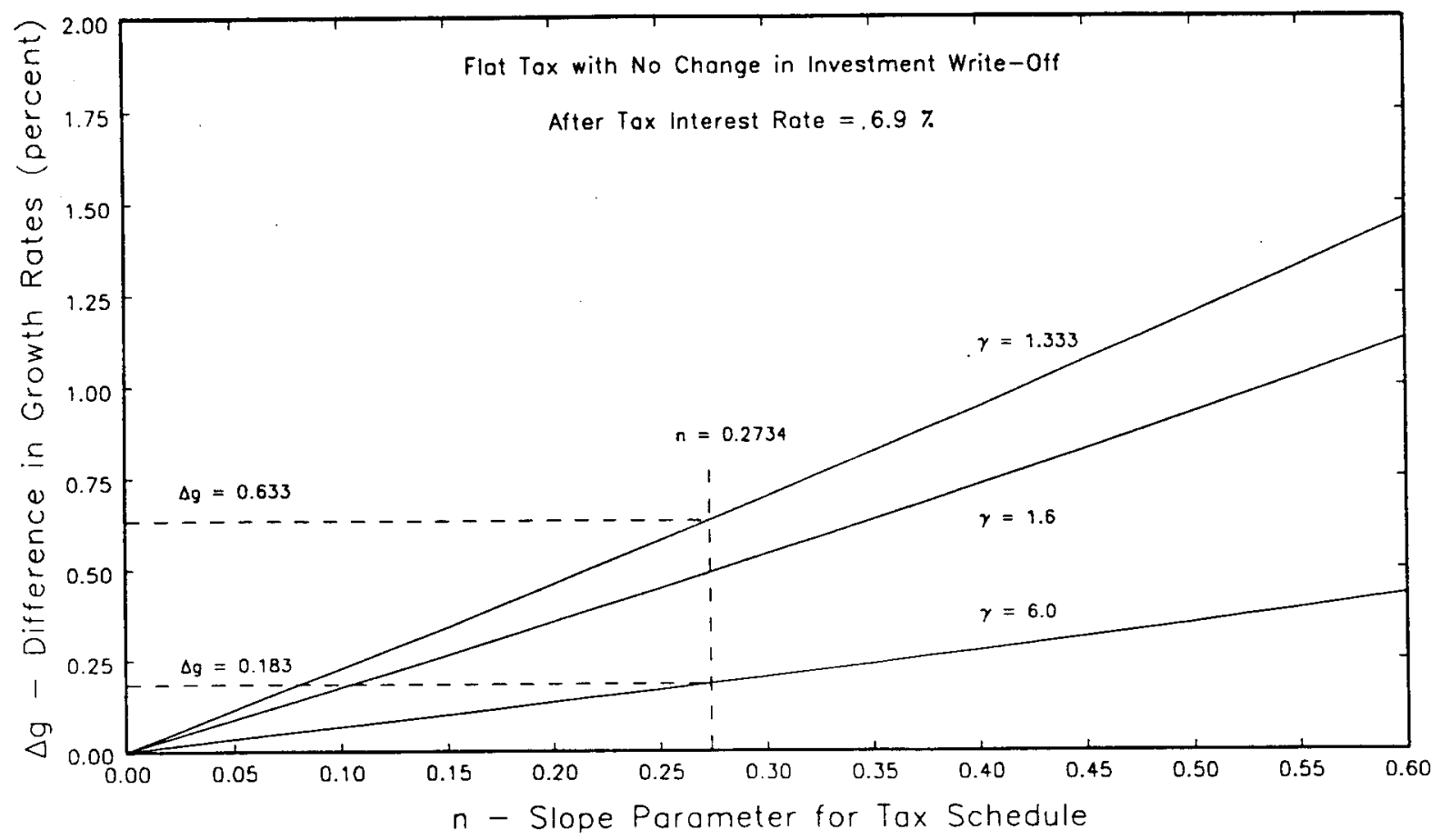

Figure 6

DIFFERENCE IN GROWTH RATES: FLAT VS PROGRESSIVE TAX SYSTEM

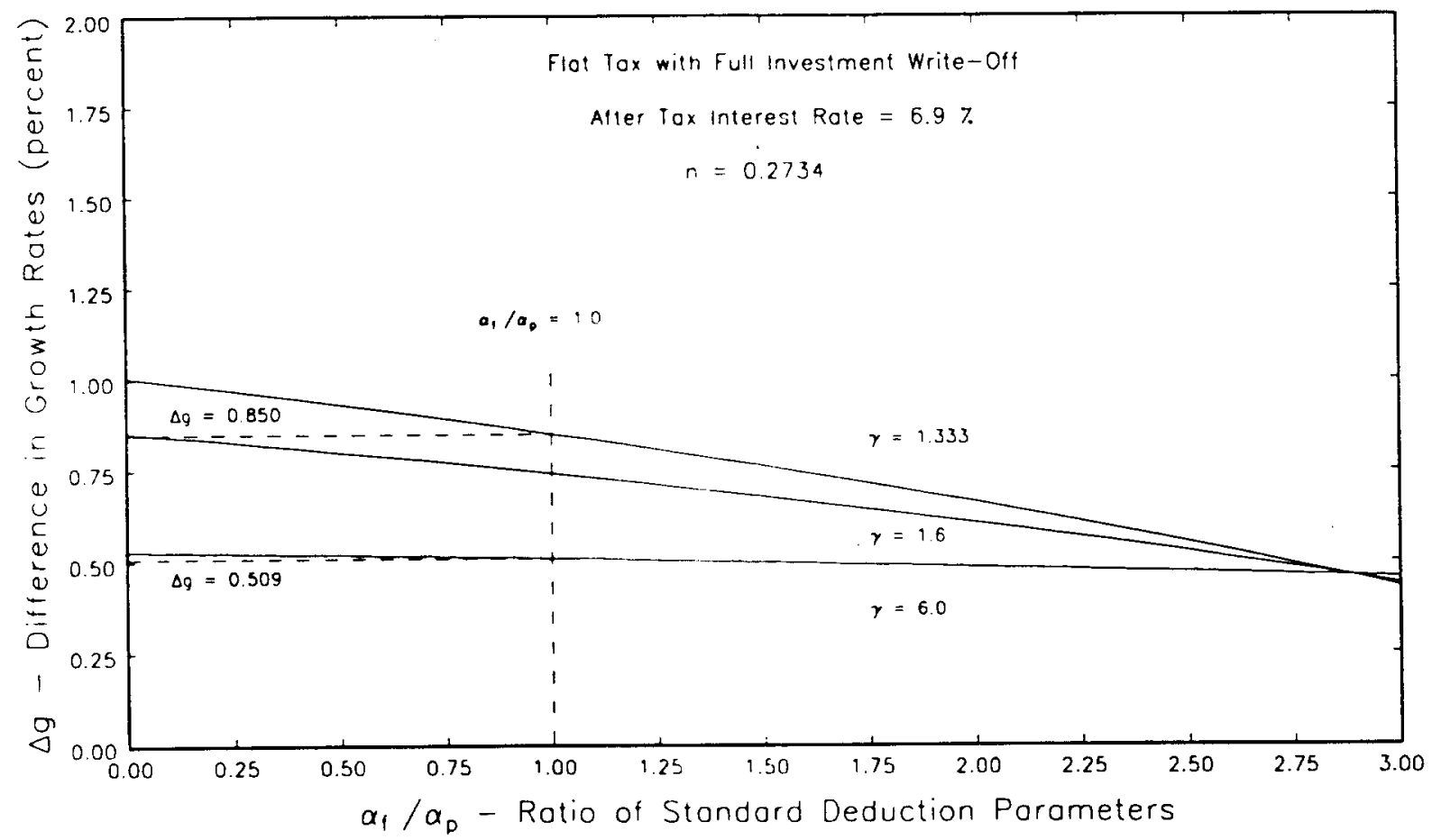


Figure 7

DIFFERENCE IN GROWTH RATES: FLAT VS PROGRESSIVE TAX SYSTEM

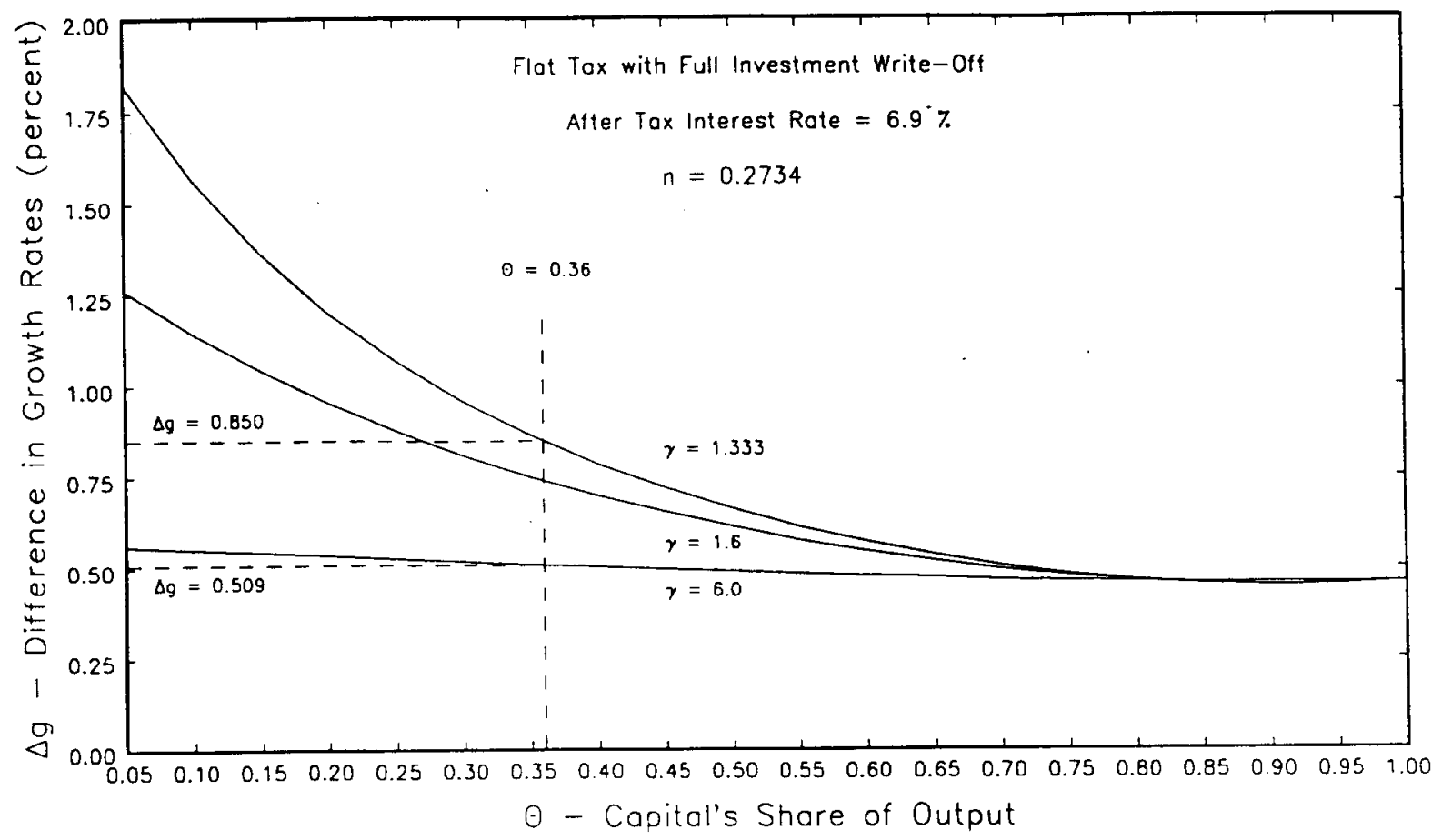

